\title{
Abnormal Branching of the Axillary Artery: Subscapular Common Trunk. A Case Report
}

\author{
Ramificación Anormal de la Arteria Axilar: Tronco Común Subescapular. Reporte de un Caso \\ "Vasudha Saralaya; ${ }^{* *}$ Theresa Joy; ${ }^{* * *}$ Sampath Madhyastha; ${ }^{* * * * *}$ Rajanigandha Vadgaonkar \& ${ }^{* * * * *}$ Shruti Saralaya
}

SARALAYA, V.; JOY, T.; MADHYASTHA, S.; VADGAONKAR, R. \& SARALAYA, S. Abnormal branching of the axillary artery: subscapular common trunk. A case report. Int. J. Morphol., 26(4):963-966, 2008.

SUMMARY: An unusual unilateral variation in the branching pattern of axillary artery was observed in a 60 year old female embalmed cadaver. The axillary artery had only two branches arising from its proximal (first) part and no branches from its remaining distal (second \& third) parts. The branches are superior thoracic (usual) and another large collateral (unusual) branch. This collateral branch is the origin of several important arteries as the circumflex scapular, thoracodorsal, posterior circumflex humeral, thoraco-acromial and lateral thoracic arteries. We propose to name this artery as common subscapular trunk. The course of this collateral artery (common subscapular trunk) and its branches and also clinical significance of this variation are discussed in the paper.

KEY WORDS: Axillary artery; Common subscapular trunk.

\section{INTRODUCTION}

The axillary artery, a continuation of the subclavian artery, begins at the outer border of the first rib, and ends normally at the inferior border of teres major muscle where onwards it continues as the brachial artery. Pectoralis minor muscle crosses it and so divides it into three parts which are proximal, posterior and distal to the muscle. Conventionally, the proximal part (first part) gives superior thoracic artery, the posterior part (second part) gives thoraco-acromial and lateral thoracic arteries and distal part (third part) gives subscapular artery, anterior and posterior circumflex humeral arteries (Standring et al., 2005).

It is not uncommon to find variations in the branching pattern of axillary artery. Many of its branches may arise by a common trunk or a branch of the named artery may arise separately (Hollinshead, 1958). On the basis of the origins of the branches, De Garis \& Swartley (1928) described 23 different types of axillary artery. According to them, there is a greater tendency in the Negro than in White persons towards clumping of the branches and arising in common.

Saeed et al. (2002) reports, a bilateral common subscapular-circumflex humeral trunk (3.8\%) emerging from the $3^{\text {rd }}$ part of the axillary artery (branching into the circumflex humeral and thoracodorsal arteries) and a bilateral thoraco-humeral trunk arising from the $2^{\text {nd }}$ part of the axillary artery $(1.9 \%)$ and branching into the lateral thoracic, circumflex humeral, subscapular and thoracodorsal arteries.

Trotter and her associates in contrast found a sex difference (common origin of two or more branches being more frequent in females), but no significant differences between the races in males. According to Compendium of Human Anatomic variations (Bergman et al., 1988), the first part of the axillary artery may, in rare cases, give rise to the subscapular artery or supply branch to the subscapular muscles. However, the remaining branches of the axillary artery arising from this subscapular artery (arising from first part) is not reported to the best of our knowledge.

There is an extensive collateral circulation associated with the subclavian and axillary arteries, particularly around the scapula. This clearly becomes of clinical significance during injury to the axillary artery. Here we present an unusual variation in which, a collateral branch arose from first part of the axillary artery and gave majority of the branches, which otherwise arise directly from the second and third parts of the axillary artery.

\footnotetext{
* Associate Professor, Dept. of Anatomy, Kasturba Medical College, Mangalore, India.

** Postgraduate student in Anatomy, Kasturba Medical College, Mangalore, India.

${ }^{* * *}$ Associate Professor, Dept. of Anatomy, Kasturba Medical College, Mangalore, India.

${ }^{* * * * *}$ Asst.Professor, Dept. of Anatomy, Kasturba Medical College, Mangalore, India.

${ }^{* * * * * *}$ Final MBBS student, Kasturba Medical College, Mangalore, India.
} 


\section{MATERIAL AND METHOD}

The variation was observed during routine dissection of a female cadaver in the dissection hall of department of Anatomy, Kasturba Medical College, Mangalore. The history of the individual and cause of the death is not known. The branches of the axillary artery are traced carefully till their termination.

\section{CASE REPORT}

At dissection the following features are noted (Figs. 1 and 2):

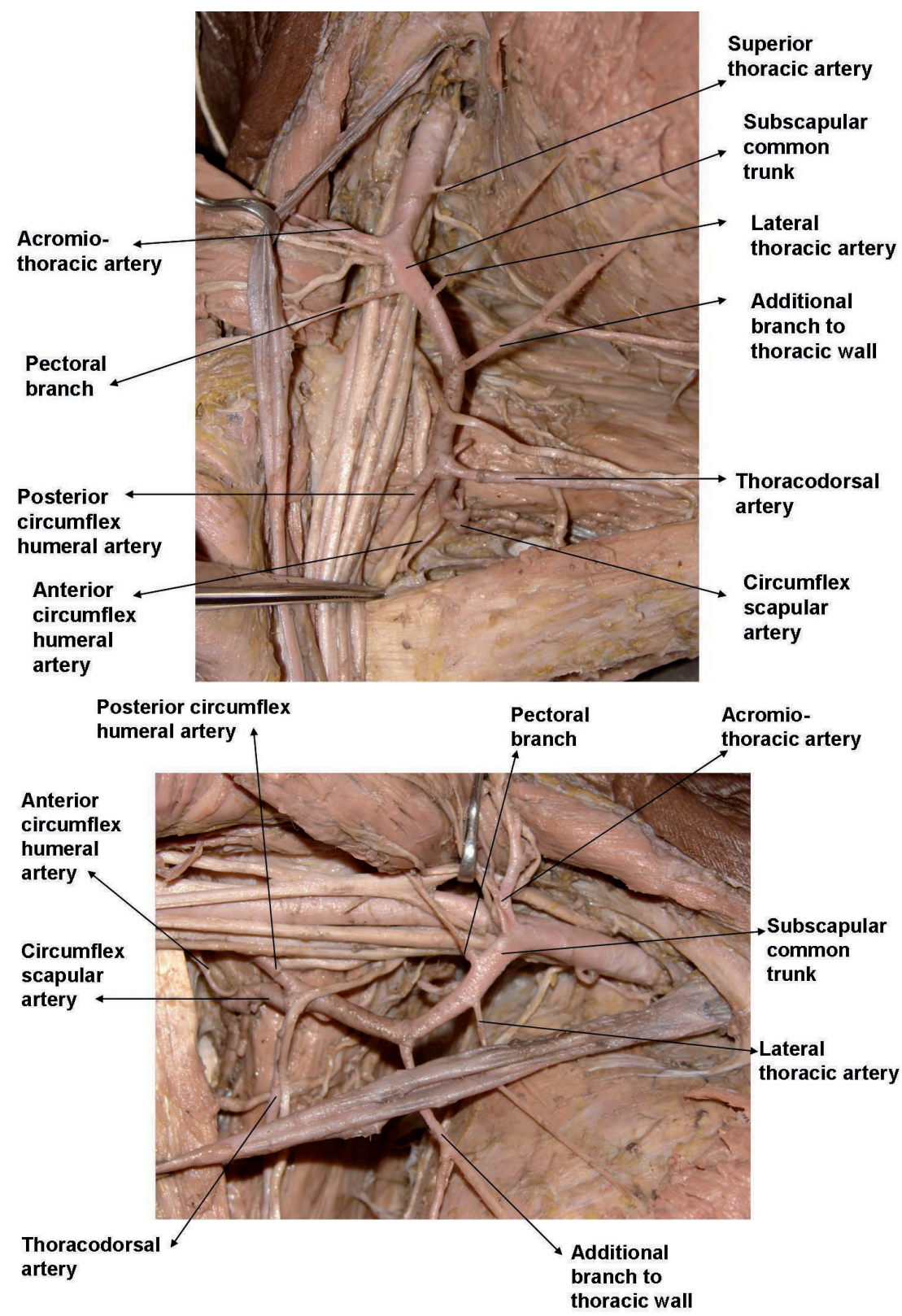

- The first part of the axillary artery gave superior thoracic artery at the normal level (near the lower border of the subclavius muscle).

- A large collateral branch arose from the axillary artery at the medial border of the pectoralis minor muscle, which gave many branches which otherwise arise from the second and third parts of the axillary artery and we propose to name this artery as common subscapular trunk

The common subscapular trunk descends medial to the axillary vein and medial root of the median nerve, resting on ventral surface of subscapular muscle under cover of pectoralis minor muscle.

- At the distal border of the subscapularis muscle, this common subscapular trunk ends by trifurcating into three branches.

- The common subscapular trunk gave thoraco-acromial (acromio-thoracic) artery immediately after its origin from the axillary artery. This branch in turn gave acromial, clavicular and deltoid branches (but not pectoral branch).

- The common subscapular trunk gave a separate pectoral branch which descends between the pectoral muscles

- The lateral thoracic artery arose from the common subscapular trunk, deep to the pectoralis minor muscle and passes medially to divide into two branches supplying thoracic wall at the level of $4^{\text {th }}$ and $5^{\text {th }}$ intercostal space. In addition to lateral thoracic artery, the common subscapular trunk also gave another muscular branch to thoracic wall proximal to the origin of the lateral thoracic artery.

- The common subscapular trunk is crossed superficially by thoracodorsal nerve.

- The three terminal branches of the collateral artery are posterior circumflex humeral artery, circumflex scapular artery and thoracodorsal arteries. 
- The posterior circumflex humeral artery descends superficial to the axillary nerve and passed through the quadrangular space.

- The circumflex scapular artery passes dorsally through upper quadrangular space.

- The thoracodorsal artery accompanied the thoracodorsal nerve along the distal border of the subscapularis muscle.

-The anterior circumflex humeral artery arose from circumflex scapular artery.

\section{DISCUSSION}

Anatomic variations in the major arteries of the upper limb have been reported. It is not uncommon to find the variation in the branching pattern of axillary artery. The review of literature shows many variations, in which two or more branches arising from the common trunk are reported. However, all the branches of axillary artery (except superior thoracic) arising from a separate collateral branch is not reported adequately except for few cases. A case reported by Venieratos \& Lolis (2001) shows common subscapular trunk gave origin to circumflex scapular, thoracodorsal, anterior and posterior circumflex humeral, profunda brachii and ulnar collateral arteries. In another report by Samuel et al. (2006) the third part of the axillary artery gave a common arterial trunk, which further gave anterior and posterior circumflex humeral, subscapular, radial collateral, middle collateral and superior ulnar collateral arteries with absence of profunda brachii artery. Our present report differs from this earlier report in branching pattern as well as course of these branches.
Such anomalous branching pattern may represent persisting branches of the capillary plexus of the developing limb buds and their unusual course may be a cause for concern to the vascular radiologists and surgeons and may lead to complications in surgeries involving the axilla and the pectoral regions. The seventh cervical segmental artery gives rise to axillary artery and any abnormality during development results in the unusual branching pattern (Wollard, 1922). Normally, in embryos of $11 \mathrm{~mm}$ length, the seventh cervical intersegmental artery enlarges and becomes the dominant vessel of axilla. C6, C7 and T1 segmental arteries and most of the longitudinal anastomoses that link up the intersegmental arteries degenerate slowly. The numerous alternatives that exist during the formation of upper limb vessels seem to be responsible for anomalous arterial branching patterns.

The knowledge of these variations is necessary for the surgeons considering the frequency of procedures performed in this region. The absence of branches from the second and third parts of axillary artery may be responsible for compromised collateral circulation between the the branches of the first part of subclavian and the branches of third part of the axillary artery in case of a block in the axillary artery beyond the first part. Even in surgeries in the pectoral region and in axilla presence of such anomalous branches ought to be kept in mind. The increasing use of invasive diagnostic and interventional procedures in cardiovascular diseases makes it important that the type and frequency of vascular variations are well documented and understood. Branches of the upper limb arteries have been used for coronary bypass and flaps in reconstructive surgery. Accurate knowledge of the normal and variant arterial pattern of the human upper extremities is important both for reparative surgery and for angiography.

SARALAYA, V.; JOY, T.; MADHYASTHA, S.; VADGAONKAR, R. \& SARALAYA, S. Ramificación anormal de la arteria axilar: tronco común subescapular, Reporte de un caso. Int. J. Morphol., 26(4):963-966, 2008.

RESUMEN: Una inusual variación unilateral en el patrón de ramificación de la arteria axilar se observó en un cadáver embalsamado de 60 años de edad. La arteria axilar tuvo sólo dos ramas derivadas de su parte proximal (primera) y no otorgó ramas de su parte distal (segunda y tercera). Las ramas son superiores torácica (habitual) y otra gran rama colateral (inusual). Esta rama colateral es el origen de varias arterias importantes como la circunfleja escapular, toracodorsal, circunfleja humeral posterior, toraco-acromial y torácica lateral. Proponemos el nombre variación arterial como tronco común subescapular. El curso de este tronco común subescapular y sus ramas y también el significado clínico de esta variación son discutidas en este trabajo.

PALABRAS CLAVE: Arteria axilar; Tronco común subescapular.

\section{REFERENCES}

Bergman, R. A.; Thompson, S. A.; Afifi, A. K. \& Saadeh, F. A. Compendium of human anatomic variations. Urban \& Schwarzenberg, Baltimore-Munich, 1988.
De Garis, C. F. \& Swartley, W. B. The axillary artery in white and negro stocks. Am. J. Anat., 41:353-97, 1928. 
SARALAYA, V.; JOY, T.; MADHYASTHA, S.; VADGAONKAR, R. \& SARALAYA, S. Abnormal branching of the axillary artery: subscapular common trunk, A case report. Int. J. Morphol., 26(4):963-966, 2008

Hollinshead, W. H. Anatomy for surgeons in general surgery of the upper limb. The back and limbs. A Heber Harper Book, New York, 1958. pp.290-300.

Saeed, M.; Rufai, A. A.; Elsayed, S. E. \& Sadiq, M. S. Variations in the subclavian-axillary arterial system. Saudi Med. J., 22(2):206-12, 2002.

Samuel, V. P.; Vollala, V. R.; Nayak, S.; Rao, M.; Bolla, S. R. \& Pammidi, N. A rare variation in the branching pattern of the axillary artery. Indian J. Plast. Surg., 39:222-3, 2006.

Standring, S.; Johnson, D.; Ellis, H. \& Collins, P. Gray's Anatomy. $39^{\text {th }}$ Ed. Churchill Livingstone, London, 2005. p.856.

Venieratos, D. \& Lolis, E. D. Abnormal ramification of the axillary artery: sub-scapular common trunk. Morphologie., 85(270):23-4, 2001.

Wollard, H. H. The development of the principal arterial stems in the forelimb of the pig. Contrib. Embryol., 14:139, 1922 .
Correspondence to:

Dr. Vasudha Saralaya

Associate Professor

Department of Anatomy

Kasturba Medical College

Mangalore 575001

INDIA

Email: vasudhas2@rediffmail.com

Received: 29-02-2008

Accepted: 04-09-2008 